\title{
Analysis on Current Situation and Forecast of Chinese Online Education Industry
}

\author{
Huawei Huang ${ }^{1}$ \\ ${ }^{1}$ Bedford School, Bedfordshire, Britain
}

\begin{abstract}
Affected by the epidemic of the COVID-19, classroom teaching has been suspended and demand of online education is increasing, which has a far-reaching impact on educational industry. The competition of online education companies is becoming fiercer. It is necessary to discuss the feasibility of online education and a future development. Therefore, finding potential of online education and analyzing encounter problems is the main purposes. Aiming at middle school students, this article uses questionnaire survey and statistic to summarize the current status of online education in China from three aspects: geographical distribution of usage, the hours and pricing issues of online education companies, consumer intentions and consumer concerns. The gray model will be applied to predict the development potential of online education and provide effective suggestions to the education community. The selected institutions are mainly educational institutions of well-known domestic brands.
\end{abstract}

\section{INTRODUCTION}

The elimination system for entrance examinations is widespread, and the consumption of educational institutions outside schools is also rising, especially the increasing popularity of online education. Although consumers accept online courses, they still value teaching quality. Since ancient times, education has been regarded as an essential industry in various countries. For society and individuals, the benefits outweigh the disadvantages. Online education is not geographically restricted and can alleviate regional differentiation to a certain extent, providing great convenience for the school students and education industry. For children from poor families, they can enjoy high quality courses in low price. Although the most important task of online education companies is to find the best choice and the best teaching plan to ensure that our teaching quality can maximize our teaching quality, there are still many problems to be improved.

This article collects data from domestic online education institutions and post online questionnaires to analysis the current situation of enterprises and consumers in the online education market. The content includes the geographical distribution of online education in China, the price of domestic education institutions' course, adverse factors in online courses and the collection of consumers intention. Finally, based on prediction of the development trend, effective suggestion will be provided for enterprises to choose the optimized method to ensure the maximum quality of online teaching services. [1]

\section{ANALYSIS}

\subsection{Model Assumption}

1) Do not consider the impact of individual extreme situations on the teaching model.

2) Do not consider the impact of some irresistible factors on the economy.

3) Do not consider the bad results caused by the company's internal personnel.

TABLE 1. PARAMETERS

\begin{tabular}{cc}
\hline symbol & Introduction of symbol \\
\hline $\boldsymbol{X}^{(\boldsymbol{\theta})}$ & Time sequence \\
$\boldsymbol{X}^{(\mathbf{1})}$ & Cumulative sequence \\
$\boldsymbol{a}$ & Development factor \\
$\boldsymbol{\mu}$ & Endogenous variable to be \\
& identified \\
$\boldsymbol{y}_{i}$ & Time sequence \\
$\hat{\boldsymbol{y}}_{\boldsymbol{i}}$ & Cumulative sequence
\end{tabular}

* Corresponding author: hhwjoe66@gmail.com 


\subsection{The Distribution of Online Courses in Chinese Different Areas}

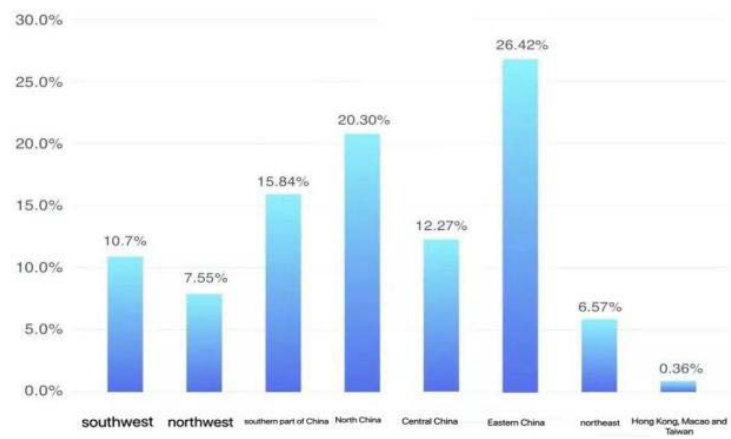

FigURE 1: REgIONAL DISTRIBUTION [2]

From the above picture, we can intuitively find that there are more people using the Internet platform in the eastern and coastal areas of China, while the proportion of people in the mainland and western regions is relatively small. It is important to draw a conclusion: coastal areas have higher technology and better education than inland areas, and there are more ways to obtain information and effective resources, so more people choose online courses.

\subsection{Course' Price of Online Education Company}

The date is from several well-known large institutions across the country. New Oriental mainly focuses on studying abroad and language training services, and the consumption power of customer groups is generally high. Xueersi and Lantian are mainly the education industry within the system, and they are quite distinctive, with a very wide audience and a particularly large number of students. Several other teaching institutions are also K12 education and training, providing more comprehensive projects.

TABLE 2. THE PRICE OF LESSON[4]

\begin{tabular}{|l|l|l|l|}
\hline \multicolumn{1}{l|}{$\begin{array}{l}\text { Junior middle } \\
\text { school }\end{array}$} & High school & \\
\hline Learn and learn & $270 / 2.5 \mathrm{~h}$ & $300 / 2.5 \mathrm{~h}$ & \\
\hline $\begin{array}{l}\text { Learning and } \\
\text { Thinking Online } \\
\text { School }\end{array}$ & $110 / 2 \mathrm{~h}$ & $120 / 2 \mathrm{~h}$ & \\
\hline $\begin{array}{l}\text { Learn and think } \\
\text { online }\end{array}$ & $150 / 2.5 \mathrm{~h}$ & $198 / 2.5 \mathrm{~h}$ & \\
\hline $\begin{array}{l}\text { New Oriental Online } \\
\text { New Oriental Peiyou }\end{array}$ & $62.5 / 2 \mathrm{~h}$ & $62.5 / 2 \mathrm{~h}$ & \\
\hline $\begin{array}{l}\text { Thinking Music } \\
\text { Education }\end{array}$ & $255 / 2.5 \mathrm{~h}$ & $240 / 2 \mathrm{~h}$ & \\
\hline Le Xuepei & $270 / 2.5 \mathrm{~h}$ & $305 / 2.5 \mathrm{~h}$ & \\
\hline Blue Sky Education & $220 / 2 \mathrm{~h}$ & $270 / 2 \mathrm{~h}$ & \\
\hline
\end{tabular}

The time arrange for junior high school is two hours and two and a half hours. By calculating the average time, price sets are as follows:

The estimated cost of Junior high school students for a 2-hour class is about 150 yuan for two hours. The estimated cost is about 240 yuan for two and a half hours. For high school students, estimated cost is about 175 yuan for two hours. Estimated cost for two and a half hours class is about 265 yuan. From the above calculated data, the relevant conclusions can be drawn: The class cost of junior high school is about 30 yuan lower than that of high school. The course for two and a half hours is about 90 yuan, which is more expensive than the two hour course.

\subsection{The Willing of Consumer Collection}

The data of the following four pie charts are all from questionnaire surveys of a thousand people from all over the country. A total of 950 people filled out the questionnaire this time, most of them were junior high school students. The questionnaire was created using a specific online platform (questionnaire star) on WeChat. Result illustrates their willingness to consume and what is the major concern about online courses.

\subsubsection{The Arrangement of Time-advice of Online Courses}

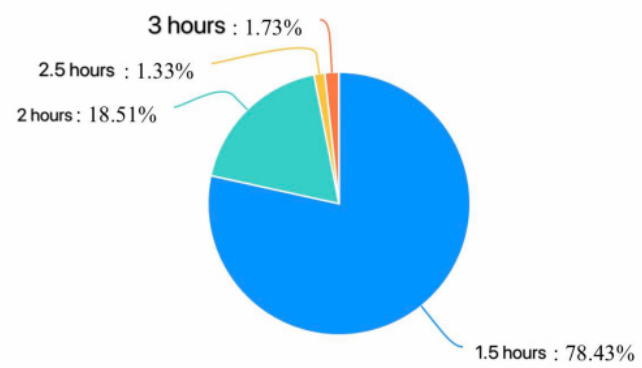

FIGURE 2: TIME-ADVICE OF ONLINE COURSES

In picture, it can be seen that students who want to take class for 1.5 hours account for $78.43 \%$. 1.5 hours are two classes of the school's regular curriculum. In this case, it is easy for students to bring learning efficiency to the highest level. The teacher can explain the knowledge points in the first hour. The second half hour can be arranged for students to practice independently. If it takes longer, students may feel physically and mentally exhausted.

\subsubsection{The Distribution of How Many Online Courses are Suitable for Students Per Day}

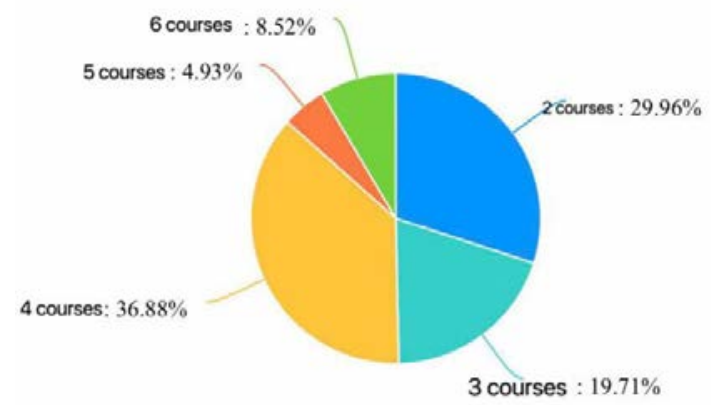

FIGURE 3: THE NUMBER OF ONLINE COURSES 
It is clearly seen that four classes are suitable for students per day. Through data analysis, students choose two classes, three classes, and the total proportion of four classes reaches more than $80 \%$. This fully shows that students do not want to take too many online classes in a day. there are several reasons: Setting too many online courses a day will seriously affect the learning effect. Too many online courses will lead to excessive physical and mental fatigue of students. Online courses are not very useful for certain students.

\subsubsection{Consumers' Concern}

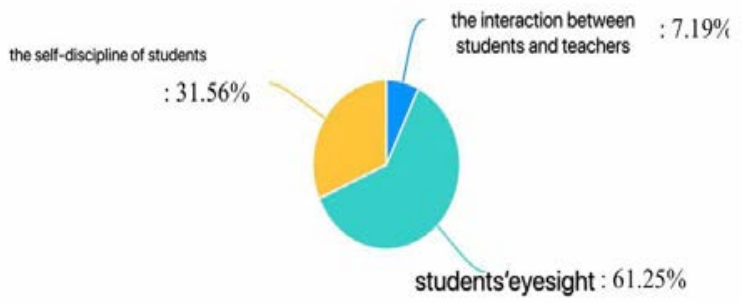

FIGURE 4: CONSUMERS CONCERN

Figure shows that the most hazard of online courses is affecting eyesight of students. According to the analysis, the reason why students are reluctant to take online courses is not only because the impact on learning efficiency, but their impaired vision. Staring at screen long time makes students unbearable. Of course, some people fill out questionnaires with strong subjective feeling.

\subsubsection{Consumers' Willingness of Class Model}

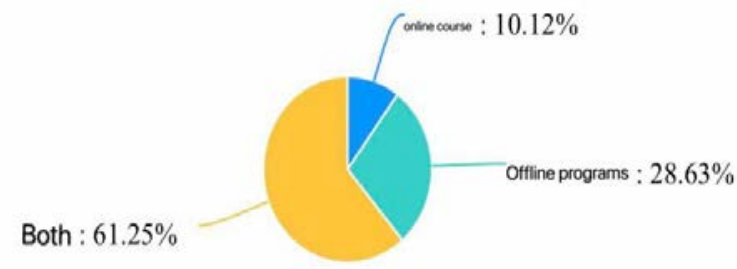

FIGURE 5: WILLINGNESS OF CLASS MODEL

Students want to choose both online and offline classes. The data shows that very few people want to choose a single online teaching and offline teaching. Most people think that the combination of the two will improve learning efficiency. there are several reasons: The combination of the two can complement the advantages and disadvantages, interact offline and watch the online courses infinitely. The combination of the two can alleviate the physical and mental fatigue caused by the online course to a certain extent.

\subsection{Prediction of the Advancement Trend Based on Gray Model}

The data are selected to make prediction through the method of gray prediction and draw a linear regression curve of the relevant model.

\subsubsection{The Number of People Using Online Courses}

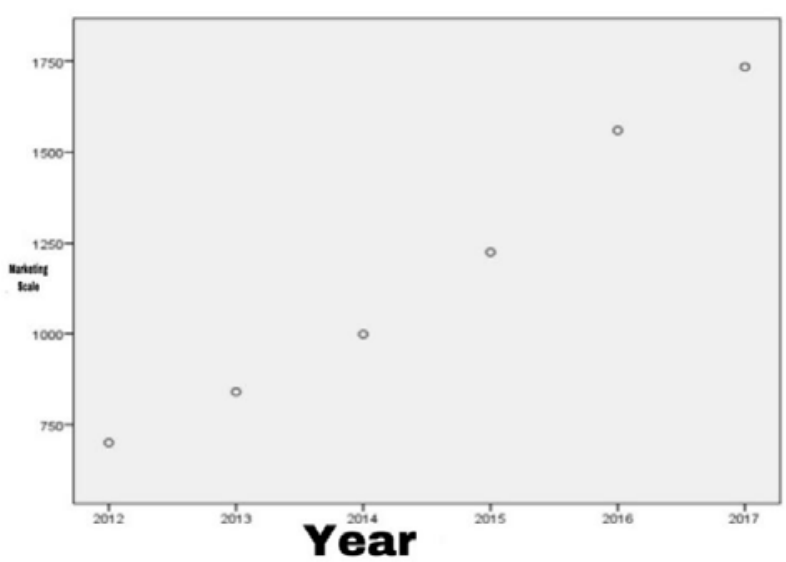

FIGURE 6: THE PROPORTION OF ONLINE COURSES IN 2012-2017

The basic principle of the gray model is as follows:

1 Let the time series have an observation value, $\mathrm{X}^{(0)} \mathrm{X}^{(0)}=\left\{\mathrm{X}^{(0)}(1), \mathrm{X}^{(0)}(2), \cdots, \mathrm{X}^{(0)}(\mathrm{n})\right\}$,

$\mathrm{X}^{(1)}(1)$ and generate a sequence for accumulation, namely, $\quad \mathrm{X}^{(1)(1)}=\sum_{\mathrm{m}-1}^{1} \mathrm{X}^{(0)}(\mathrm{m}), \quad \mathrm{l}=1,2, \cdots, \mathrm{n}$. The corresponding differential equation of the $\operatorname{GM}(1,1)$ model is: $\frac{\mathrm{dx}^{(1)}}{\mathrm{dl}}=\mathrm{ax}^{(1)}=\mu$. Among them, the parameter to be identified, also known as the development coefficient, is the endogenous variable to be identified. The discrete time response function of gray prediction is: \[ \mathrm{X}^{(1)}(1+1)=\left\{\mathrm{X}^{(0)}(1)-\frac{\mu}{\mathrm{a}}\right\} * \mathrm{e}^{-\mathrm{a}}+\frac{\mu}{\mathrm{a}} \text {, Reducing the } \]
accumulated $\widehat{\mathrm{X}}^{(0)}(1+1)=\widehat{\mathrm{X}}^{(1)}(1+1)-\widehat{\mathrm{X}}^{(1)}(1)$ value,
get: $(1=1,2, \cdots, n)$

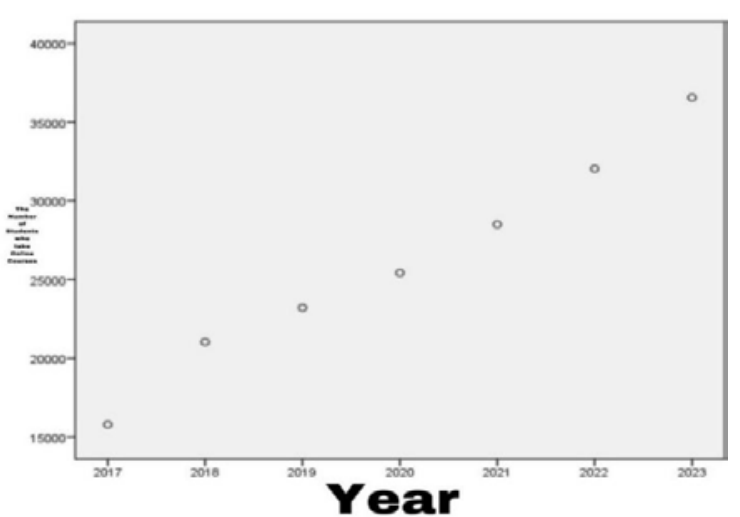

FIGURE 7: ONLINE COURSES IN THE NEXT SIX YEARS

From these two figures, It can be concluded that with the development of information technology, the number of people using online courses has shown an obvious upward trend. Therefore, the teaching mode of online courses is an indispensable part of future education.[3] 


\subsubsection{The Number of Extracurricular Tutoring}

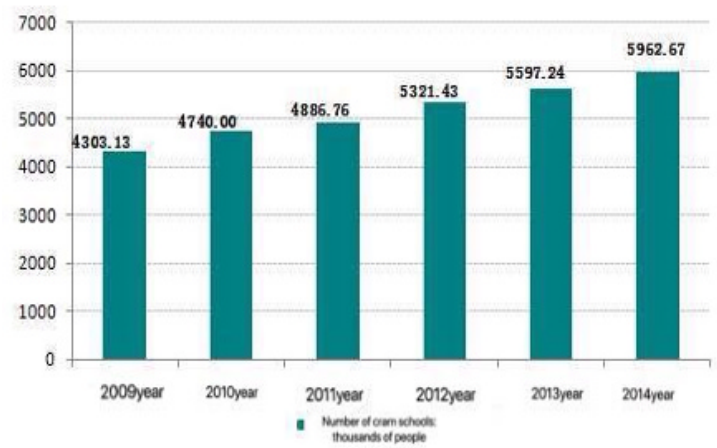

Figure 8: NATIONAL TUTORING[2]

Through the analysis of the histogram, It is easy to find that during the five years from 2009 to 2014, the number of extracurricular tutoring shows an upward trend. The education industry is constantly expanding, and consumers entering the education industry are constantly increasing.

\section{CONCLUSION}

With the development of information technology, the number of people participating online courses has shown an obvious upward trend. The number of online education participants in China has increased year by year. Due to regional differences, the inland areas of our country are cannot easily obtain forefront education resources. If the distance education is adopted, this drawback can be greatly alleviated. It is clearly seen that combining offline and online classes has to be take into consideration. According to the data of education enterprises, companies should pay particular attention to the coastal areas' education in the next stage. The demand in these areas is high, so consumption will be high. At the same time, educational institutions should reasonably set the charging price and the duration of online courses. For education companies, the biggest hazard of online courses is students' eyesight, so education companies should consider how to solve eyesight problems while ensuring the quality of teaching. The most likely problems encountered in the implementation of this program: Technical problems lead to a decline in the quality of online courses. The unconscious behavior of students leads to the decline of teaching quality. The complexity of the model leads to cost too much time and effort.

\section{SUGGESTION}

The price of choosing online courses is about 200. The fees for high schools must be higher than those for junior high schools. The difficulty of courses increases and the requirements for teachers are higher. They can take live and offline live lessons. Students with conditions permit, participate in offline lectures, and watch live streams when conditions do not allow.

Educational institutions can provide more interactive services. For example, the teacher can try to communicate with the students to solve the problem during the class, which can ensure the student's learning efficiency. Secondly, the teacher can arrange some homework in the class from time to time, so that the students do not have to look at the computer all the time.

Take online teaching as the mainstay, supplemented by offline counseling. Students can reserve offline classrooms for question answering and interaction. This model not only greatly reduces the time cost and labor cost, but also cultivates students' independent learning ability. Since students can solve the problems raised by the teacher on the spot in the classroom, and there is no need to spend more time to contact the teacher.

\section{ACKNOWLEDGEMENT}

I sincerely thank those who provided help for this scientific research. Without their support, it is difficult to complete this research.

\section{REFERENCES}

1. Forward-looking economist.ecoapp.qianzhan.com.

2. Ceic Global Macroeconomic Data. aisite. wejianzhan.com.

3. Lu Yao, Sun Wanfa. Investigation and research on the strength of teachers in extracurricular tutoring institutions in primary and secondary schools [J]. Education Science Forum, 2020(17): 77-80.

4. Chen Yu, Li Mingwu. Research on the marketing strategy of extracurricular tutoring institutions in elementary and middle schoolsTaking Owen Education as an example[J]. Industry and Technology. Forum, 2019, 18(24): 265-266. 